Check for updates

Cite this: RSC Adv., 2018, 8, 13259

Received 25th December 2017

Accepted 13th March 2018

DOI: $10.1039 / c 7 r a 13632 c$

rsc.li/rsc-advances

\section{Synthesis and physical properties of brominated hexacene and hole-transfer properties of thin-film transistors $\dagger$}

\author{
Motonori Watanabe, (D) *a Takaaki Miyazaki, ${ }^{\text {t }}$ Toshinori Matsushima, ${ }^{\text {acd }}$ \\ Junko Matsuda, ${ }^{a}$ Ching-Ting Chein, ${ }^{\mathrm{e}}$ Masahiko Shibahara, ${ }^{\mathrm{f}}$ Chihaya Adachi, (D) abcdg \\ Shih-Sheng Sun, ${ }^{\mathrm{e}}$ Tahsin J. Chow ${ }^{\star \mathrm{eh}}$ and Tatsumi Ishihara (D) ag
}

\begin{abstract}
A halide-substituted higher acene, 2-bromohexacene, and its precursor with a carbonyl bridge moiety were synthesized. The precursor was synthesized through 7 steps in a total yield of $2.5 \%$. The structure of precursor and thermally converted 2-bromohexacene were characterized by solid state NMR, IR, and absorption spectra, as well as by DFT computation analysis. It exhibited high stability in the solid state over 3 months, therefore can be utilized in the fabrication of opto-electronic devices. The organic thinfilm transistors (OFETs) were fabricated by using 2-bromohexacene and parent hexacene through vaccum deposition method. The best film mobility of 2-bromohexacene was observed at $0.83 \mathrm{~cm}^{2} \mathrm{~V}^{-1}$ $\mathrm{s}^{-1}$ with an on/off ratio of $5.0 \times 10^{4}$ and a threshold of $-52 \mathrm{~V}$, while the best film mobility of hexacene was observed at $0.076 \mathrm{~cm}^{2} \mathrm{~V}^{-1} \mathrm{~s}^{-1}$ with an on/off ratio of $2.4 \times 10^{2}$ and a threshold of $-21 \mathrm{~V}$. AFM measurement of 2-bromohexacene showed smooth film formation. The averaged mobility of 2bromohexacene is 8 fold higher than the non-substituted hexacene.
\end{abstract}

\section{Introduction}

Acenes are amongst the most representative hydrocarbons for analysing the physical properties of polycyclic hydrocarbon materials. ${ }^{1}$ Along with the increase in the number of aromatic benzene rings, acenes exhibit a reduction of both the HOMOLUMO gap and the reorganisation energy. ${ }^{2}$ The chemistry of acenes higher than pentacene, particularly their open-shell characteristics $^{3}$ and high charge transport properties, has attracted considerable attentions. Hence, these compounds and their analogs ${ }^{4}$ such thieonoacene based semiconductor ${ }^{5}$ are

anternational Institute for Carbon Neutral Energy Research, Kyushu University, 744 Motooka, Nishi-ku,, Fukuoka 819-0395, Japan. E-mail: mwata@i2cner.kyushu-u.ac.jp ${ }^{b}$ Education Center for Global Leaders in Molecular Systems for Devices, Kyushu University, 744 Motooka Nishi-ku, Fukuoka 819-0395, Japan

${ }^{c}$ Center for Organic Photonics and Electronics Research (OPERA), Kyushu University, 744 Motooka, Nishi-ku, Fukuoka, Japan

'Japan Science and Technology Agency (JST), ERATO, Adachi Molecular Exciton Engineering Project, 744 Motooka, Nishi-ku, Fukuoka 819-0395, Japan

${ }^{e}$ Institute of Chemistry, Academia Sinica, No. 128, Academia Road Sec 2, Nankang, Taipei 11529, Taiwan

${ }^{f}$ Division of Natural Sciences, Faculty of Science and Technology, Oita University, Dannoharu 700, Oita, Japan

${ }^{g}$ Department of Applied Chemistry, Faculty of Engineering, Kyushu University, Nishi-ku, Fukuoka 819-0395, Japan

${ }^{h}$ Department of Chemistry, Tunghai University, Taichung 40704, Taiwan

$\uparrow$ Electronic supplementary information (ESI) available: Absorption spectra, DFT results, XRD, and NMR data. See DOI: 10.1039/c7ra13632c suitable for use in organic electronic devices such as organic field-effect transistors. ${ }^{6-8}$ The extended $\pi$-conjugation of higher acenes also induce an interesting phenomenon of singlet fission that can be used on light harvesting. ${ }^{9}$ Bulky substituents can enhance the thermal and photo-stability of acenes by lowering the radical characteristic in the ground state. ${ }^{10}$ The isolation of higher acenes, from hexacene to nonacene and derivatives, has been achieved by applying this strategy. The modification of physical properties of acenes in the solid state requires a crystal engineering approach; however, their isolation steps are either difficult or tedious in order to obtain qualified structures due to their high thermal and light sensitivity in solutions. ${ }^{\mathbf{1 1 , 1 2}}$ To overcome the difficulty, stable precursors of acenes are prepared first, which can then be converted to the corresponding acenes quantitatively in demand through either a thermal or a photo-driven process. ${ }^{\mathbf{1 3 , 1 4}}$ The synthesis of nonacene derivatives has been achieved by this approach utilising a diketone precursor through photo-induced transformation. ${ }^{15}$ Recently, the dimer structure of heptacene was converted to heptacene via a thermal retro-cyclization reaction, therefore showing its feasibility for further processes. ${ }^{16}$ The precursor method can be used to produce higher acenes in large quantity that is required to become usable materials. Acenes have certain valuable potential applications, such as organic semi-conductors, ${ }^{17}$ singlet fission materials, ${ }^{18,19}$ and organic biradical sources. ${ }^{15}$

Previously, our group has developed the method of producing higher acene molecules from either monoketone 


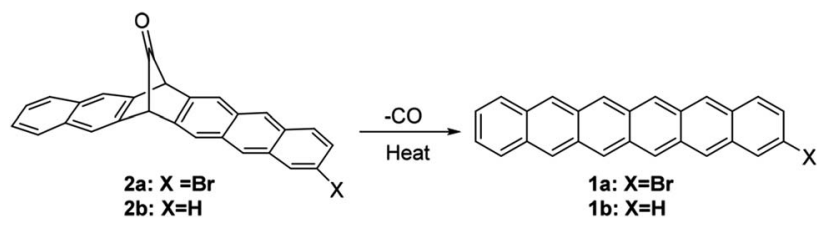

Fig. 1 The synthesis of 2-bromohexacene from its monoketone precursor.

precursors ${ }^{20}$ or from diethylketomalonate precursors. ${ }^{21}$ Both types of precursor can be cleanly converted to hexacene either thermally or photo-chemically. In addition, our group has generated halide-substituted tetracene $e^{22}$ and pentacene ${ }^{23}$ from their corresponding monoketone precursors. They were used successfully as the semiconductors in electronic devices. In these devices, single crystal bromopentacene device exhibits a significant superior hole mobility $\left(>5 \mathrm{~cm}^{2} \mathrm{~V}^{-1} \mathrm{~s}^{-1}\right)$ to the parent pentacene $\left(1.4 \mathrm{~cm}^{2} \mathrm{~V}^{-1} \mathrm{~s}^{-1}\right)$. Such a high performance is comparable with other related materials, such as triisopropylsilylethynylpentacene $\left(>1 \quad \mathrm{~cm}^{2} \quad \mathrm{~V}^{-1} \quad \mathrm{~s}^{-1}\right),{ }^{24-26}$ alkylated dinaphtho[2,3-b:2', $\left.3^{\prime}-f\right]$ thieno[3,2-b] thiophenes $\left(>10 \mathrm{~cm}^{2} \mathrm{~V}^{-1}\right.$ $\left.\mathrm{s}^{-1}\right),,^{27,28}$ and the crystal of tetracene analogous of rubrene $(>18$ $\left.\mathrm{cm}^{2} \mathrm{~V}^{-1} \mathrm{~s}^{-1}\right){ }^{29,30}$ In previous reports, the charge mobility of hexacene and derivatives were measured in the devices either made with single crystals, ${ }^{21}$ or with crystalline thin films prepared through solution method. ${ }^{22,31}$ However, the physical properties and transistor characteristics of hexacene thin film that is prepared by vacuum deposition method have not yet been reported.

It is believed that the bromine substituent can provide a suitable size to improve crystal packing. Judged by the past high-performance of brominated tetracene and pentacene, it is therefore in demand to explore the possibility of brominated analogue of hexacene. In this regard, the brominated analogue of hexacene, i.e., 2-bromohexacene (1a), is synthesized and its charge-transport property is examined. Precursor $\mathbf{2 a}$ is cleanly converted to 1a by thermal decomposition, and 1a exhibits high thermal stability in the dark over 90 days (Fig. 1). This is the first example of the charge-transport property of a stable vacuumdeposited thin-film of hexacene and halogenated hexacene for electronic devices.

\section{Results and discussion}

\subsection{Synthesis}

The synthesis of 2a is shown in Scheme 1. Dimethylfulvene derivative 3 and benzoquinone $\mathbf{4}$ were treated with $s$-tetrazine, affording diketone $\mathbf{5}$ as an endo-exo mixture, then the double bond of $\mathbf{5}$ was reduced using zinc in acetic acid, affording adduct $\mathbf{6}$. The aldol reaction of $\mathbf{6}$ with dialdehyde 7 afforded diketone 8 as an endo compound in $17 \%$ yield (from 3, three steps). Pure endo-8 was crystallized probably due to steric influence by the bromo-substituent. It was reduced by $\mathrm{NaBH}_{4}$, and further treatment with $\mathrm{POCl}_{3} /$ pyridine afforded aromatic compound 9 in $48 \%$ yield (from 8 , two steps). The exo-double bond was treated with $\mathrm{OsO}_{4}$ to give a diol, followed by treatment

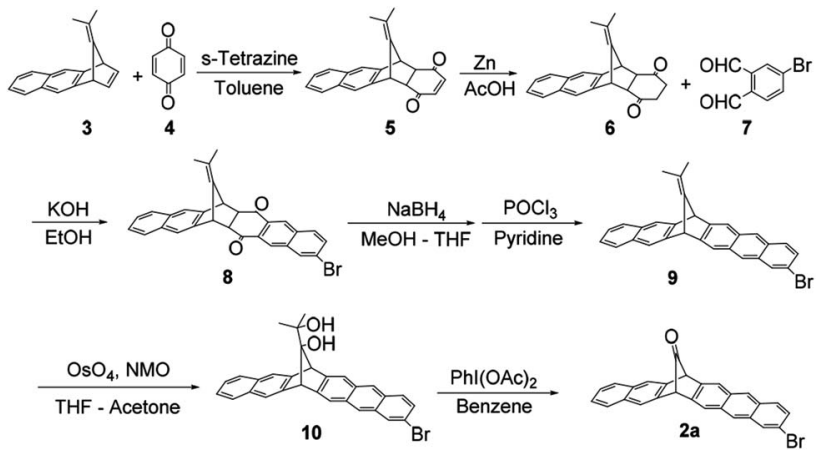

Scheme 1 Synthetic route of $2 a$

with $\mathrm{PhI}(\mathrm{OAc})_{2}$ to give desired $2 \mathrm{a}$ in $31 \%$ yield. The total yield was $2.5 \%$ in 7 steps.

The absorption spectrum of $2 \mathrm{a}$ in 1,2,4-trichlorobenzene exhibited characteristic ${ }^{1} \mathrm{~A}-{ }^{1} \mathrm{~L}_{\mathrm{a}}$ transitions of the anthracene chromophore at $353,371,391$ and $408 \mathrm{~nm}$, with vibrionic progressions, which were red-shifted from the peaks of parent 2b at 350, 368 and $391 \mathrm{~nm}$ in the 1,2,4-trichlorobenzene solution (Fig. S1 $\dagger$ ). When the solution of 2 a was heated at $230^{\circ} \mathrm{C}$, the solution changed from colorless to pale-green, which exhibited characteristic acene vibration absorption bands at 573, 623 and $679 \mathrm{~nm}$. However, this colour changed to yellow within a few minutes owing to the dimerization or oxidation of $\mathbf{1 a}$.

\subsection{Physical properties}

The absorption maximum in the visible range was observed at $679 \mathrm{~nm}$, whereas parent hexacene $1 \mathbf{b}$ exhibited the peak maximum at $675 \mathrm{~nm}$ in 1,2,4-trichlorobenzene (Fig. S1†). The peaks were red-shifted from those of parent hexacene $\mathbf{1 b}$ by $4 \mathrm{~nm}$, indicating the reduction of HOMO-LUMO gap of 1a by the bromo substituent. This phenomenon has similarly been observed in the pairs of tetracene (473 nm in THF) and 2-bromotetracene ( $477 \mathrm{~nm}$ in THF), ${ }^{22}$ as well as pentacene $(575 \mathrm{~nm}$ in THF) and 2-bromopentacene (578 nm in THF). ${ }^{23}$ To compare with the reported hexacene analogues, the peak maximum was shown to be red-shifted from that of pentaceno[2,3-b]thiophene $(640 \mathrm{~nm} \text { in } o \text {-DCB })^{30}$ due to the increase of aromaticity. In comparison with other substituent group effect, however, it showed a blue shift from those of tricyclohexylsilylethynyloctafluorohexacene $\left(\begin{array}{ll}725 & \mathrm{~nm}\end{array}\right),{ }^{31} \quad$ tri-tert-butylsilylethynyhexacene $(738 \mathrm{~nm}),{ }^{32,33}$ and trialkylsilylethynyl-azahexacene (825-842 $\mathrm{nm}$ in hexane) ${ }^{34}$ due to the electron-donating effect of the trialkylsilylethynyl acetylene units.

In the thermal gravimetric analysis (TGA) profile of 2a, the first weight loss $(8.5 \%$, calcd $6.5 \%)$ was observed at approximately $200{ }^{\circ} \mathrm{C}$ to generate $1 \mathrm{a}$. The thermal weight loss profile did not change up to $360^{\circ} \mathrm{C}$. Then it was followed by the second weight loss caused by the vaporisation as well as the decomposition of 1a at temperatures greater than $400{ }^{\circ} \mathrm{C}$ (Fig. 2a). Decarbonylation at $200{ }^{\circ} \mathrm{C}$ was confirmed by infrared (IR) spectroscopy, which revealed the disappearance of the characteristic $\mathrm{C}=\mathrm{O}$ stretching band at $1786 \mathrm{~cm}^{-1}$ after heating at $230{ }^{\circ} \mathrm{C}$ (Fig. 2b). The high-resolution FAB-MS spectrum revealed 
(a)

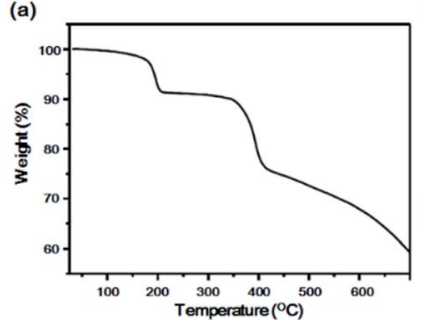

(c)

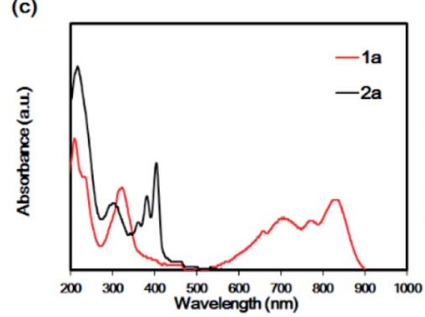

(b)

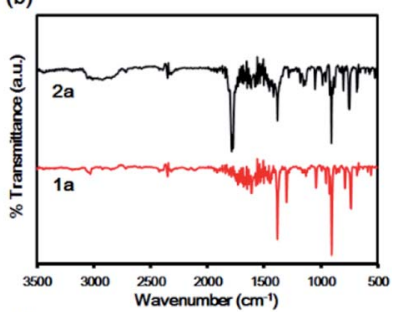

(d)

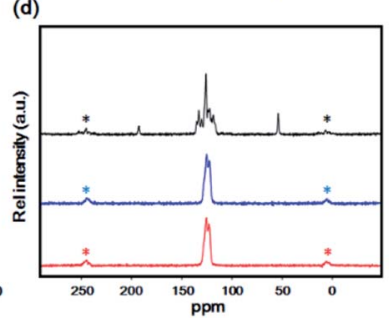

Fig. 2 (a) TGA profile of $2 a$ under nitrogen. Heating rate was $10^{\circ} \mathrm{C} \mathrm{min}^{-1}$. (b) IR spectra of $2 \mathrm{a}$ (black) and after heating at $230{ }^{\circ} \mathrm{C}$ for conversion to 1a (red) under ambient conditions. (c) Reflectance absorption spectra of drop-casted $2 \mathrm{a}$ on a quartz plate (black) and after heating at $230{ }^{\circ} \mathrm{C}$ for conversion to $1 \mathrm{la}$ (red) under ambient conditions. (d) Solid-state ${ }^{13} \mathrm{C}$ CP-MAS spectra of $2 \mathrm{a}$ (black), 1a (blue) and $1 \mathrm{a}$ after 90 days in the dark (red). The asterisk denotes the spinning side band.

a molecular ion signal at $m / z 406.0387$ (M+, calcd 406.03571, error $=+7.4 \mathrm{ppm}$ ), which corresponded to $\mathbf{1 a}$. The purity was also confirmed by correct elemental analysis. The absorption spectra of $2 \mathbf{a}$, fabricated by drop-casting a saturated chlorobenzene solution on a quartz substrate, exhibited a similar vibration structure to that of $2 \mathbf{a}$ in solution, with characteristic peaks at 403, 380 and $364 \mathrm{~nm}$, indicative of the fabrication of film of $2 \mathrm{a}$. In contrast, after heating at $230{ }^{\circ} \mathrm{C}$ under nitrogen, a broad band was observed at 500-900 $\mathrm{nm}$, and the peaks at 360-400 $\mathrm{nm}$, which are characteristic of the anthracene moiety, disappeared.

These structures were different from that of $1 \mathrm{a}$ in solution. Film 1a exhibited characteristic peaks at 833 and 776 and at 708 and $661 \mathrm{~nm}$. These peaks exhibited the appearance of Davydov splitting effect. ${ }^{20,21,35}$ The same pattern appeared in other related acene structures in the solid state, including parent $\mathbf{1 b}$, at $840 \mathrm{~nm}, 765 \mathrm{~nm}, 708 \mathrm{~nm}$ and $654 \mathrm{~nm} .^{20}$ The first bands at 833 and $775 \mathrm{~nm}$ corresponded to the $0-0$ band, and those at 708 and $654 \mathrm{~nm}$ corresponded to the $0-1$ band (Fig. 2c). The high thermal stability of $\mathbf{1 b}$ in the solid state was confirmed by solid-

state NMR that maintained invariant over 1 month. $^{\mathbf{1 3}}$ Comparing it with heptacene under a similar situation, the latter dimerised slightly after 1 month. ${ }^{16}$ To verify the thermal stability of $1 \mathrm{a},{ }^{13} \mathrm{C}$ CP-MAS NMR spectra were recorded for monitoring the variation of the carbon skeleton. Compound 2a exhibited three main peaks at 193.2 (bridge position of $\mathrm{C}=\mathrm{O}$ ), 137-114 (aromatic carbon atoms) and 54.4 ppm (bridgehead tertiary carbon atom). After the conversion to 1a, the spectrum exhibited aromatic carbon peaks at $\mathbf{1 2 5 . 7}$ and 122.9 ppm only, indicating a quantitative transformation. After maintaining 1a for 90 days in the dark under air atmosphere, no changes were observed in the CP-MAS spectrum, indicative of the high thermal stability of 1a (Fig. 2d). This high thermal stability can be compared with the reported property of hexacene ( $>1$ month in dark) ${ }^{20}$ and tricyclohexylsilylethynylhexacene (several month). ${ }^{33}$ The film of 1 a was grown by vacuum sublimation and exhibited a structure similar to the film in Fig. 2c (Fig. S3†). The ionisation potential $\left(E_{\text {ip }}\right)$ and electron affinity $\left(E_{\text {ea }}\right)$ of the film 1a were -5.24 and $-3.30 \mathrm{eV}$, respectively, while those of $\mathbf{1 b}$ were -4.81 and $-2.70 \mathrm{eV}$, respectively (Fig. $\mathrm{S} 4 \dagger$ ). The $E_{\mathrm{ip}}$ of thin film $1 \mathbf{b}(-4.81 \mathrm{eV})$ was consistent with that of the crystalline powder reported previously $(-4.96 \mathrm{eV}) .{ }^{\mathbf{1 4}}$ The energy gap of $1 \mathrm{a}(1.94 \mathrm{eV})$ was less than that of $\mathbf{1 b}(2.11 \mathrm{eV})$. Theoretical computation results (DFT, B3LYP/6-31G(d) level) revealed the HOMO and LUMO of $\mathbf{1 b}$ to be -4.68 and $-2.90 \mathrm{eV}$, respectively, while the corresponding values for $1 \mathrm{a}$ were $-4.81 \mathrm{eV}$ and $-3.04 \mathrm{eV}$, respectively. The HOMO and LUMO were lowered by bromination compared with those of 1a, indicative of the electronwithdrawing effect by the bromo substituent. The HOMOLUMO gap of $1 \mathrm{a}$ was $1.77 \mathrm{eV}$, whereas that of $\mathbf{1 b}$ was $1.78 \mathrm{eV}$, supporting the experimental results (Table 1).

\subsection{Charge transport properties}

The properties of organic field-effect transistors (OFETs) made with the films of $\mathbf{1} \mathbf{a}-\mathbf{b}$ were examined. The OFET devices were fabricated by vacuum sublimation of $\mathbf{1 a}-\mathbf{b}$ under a pressure of 8 $\times 10^{-6}$ torr to deposit the thin films on an $\mathrm{HMDS} / \mathrm{SiO}_{2} / \mathrm{Si}$ substrate, followed by the deposition of gold electrodes on the top of the films. The film thickness of $1 \mathbf{a}-\mathbf{b}$ was $60 \mathrm{~nm}$. The channel dimension of the source/drain electrodes was $45 \times$ $2000 \mu \mathrm{m}$. The output parameters were measured on a selected film across a source-drain channel, followed by the plot of drain current $\left(I_{\mathrm{D}}\right)$ versus drain source voltage $\left(V_{\mathrm{DS}}\right)$ at various gate voltages $\left(V_{\mathrm{G}}\right)$. The corresponding transfer characteristics were plotted for $\log \left(I_{\mathrm{D}}\right)$ versus $V_{\mathrm{G}}$ at a $V_{\mathrm{DS}}$ of $-100 \mathrm{~V}$ and $I_{\mathrm{D}}$ versus $V_{\mathrm{DS}}$

Table 1 Physical properties of $1 a-b$

\begin{tabular}{|c|c|c|c|c|c|c|c|c|}
\hline Sample & $\begin{array}{l}\text { Ionization } \\
\text { potential } \\
\left(E_{\mathrm{ip}}, \mathrm{eV}\right)^{a}\end{array}$ & $\begin{array}{l}\text { Electron } \\
\text { affinity } \\
\left(E_{\text {ea }}, \mathrm{eV}\right)^{b}\end{array}$ & $\begin{array}{l}\text { Energy gap } \\
(\mathrm{eV})^{c}\end{array}$ & $\begin{array}{l}\text { Optical gap } \\
(\mathrm{eV})^{d}\end{array}$ & $\begin{array}{l}\text { HOMO } \\
\left(E_{\mathrm{H}}, \mathrm{eV}\right)^{e}\end{array}$ & $\begin{array}{l}\text { LUMO } \\
\left(E_{\mathrm{L}}, \mathrm{eV}\right)^{e}\end{array}$ & $\begin{array}{l}\text { Energy gap } \\
(\mathrm{eV})^{f}\end{array}$ & $\begin{array}{l}\text { Reorganization } \\
\text { energy }\left(\lambda^{+}, \mathrm{meV}\right)^{e}\end{array}$ \\
\hline $\mathbf{1 b}$ & -4.81 & -2.70 & 2.11 & 1.41 & -4.68 & -2.90 & 1.78 & 79 \\
\hline
\end{tabular}

${ }^{a}$ Estimated by photoelectron yield spectroscopy. ${ }^{b}$ Estimated by low-energy inverse photoemission spectroscopy. ${ }^{c} E_{\mathrm{ip}}-E_{\mathrm{ea}} \cdot{ }^{d}$ Estimated by the edge of absorption spectra of thin-film. ${ }^{e}$ B3LYP/6-31G(d). ${ }^{f} E_{\mathrm{H}}-E_{\mathrm{L}}$. 

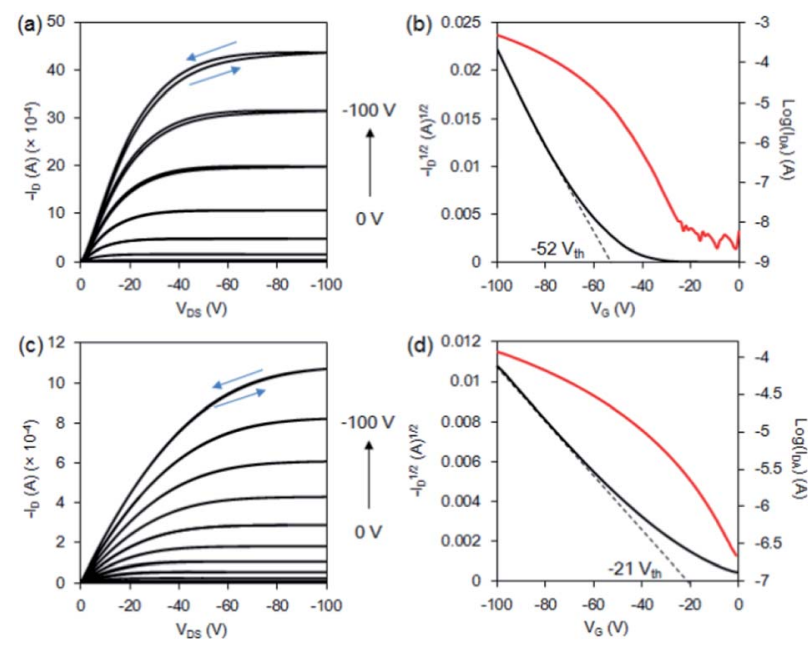

Fig. 3 Vacuum-deposited thin-film OFET made using 1a. (a) Output characteristics, where $D$ and $S$ are the drain and source, respectively. (b) Transfer characteristics recorded at $V_{D S}=-100 \mathrm{~V}$, where $G$ is the gate, and the vacuum-deposited thin-film OFET was made using $1 \mathrm{~b}$. (c) Output characteristics, where $D$ and $S$ are the drain and source, respectively. (d) Transfer characteristics recorded at $V_{D S}=-100 \mathrm{~V}$, where $G$ is the gate.

in the saturation mode. The field-effect hole mobility of 1a was measured, and the mobility values ranged from 0.21 to $0.83 \mathrm{~cm}^{2}$ $\mathrm{V}^{-1} \mathrm{~s}^{-1}$ with threshold voltages of -50 to $-69.3 \mathrm{~V}$. The averaged performance of six independent devices was $0.52 \mathrm{~cm}^{2} \mathrm{~V}^{-1} \mathrm{~s}^{-1}$ and a threshold of $-56.3 \mathrm{~V}$. The best mobility of bromohexacene $1 \mathrm{a}$ was observed at $0.83 \mathrm{~cm}^{2} \mathrm{~V}^{-1} \mathrm{~s}^{-1}$ with an on/off ratio of $5.0 \times 10^{4}$ and a threshold of $-52 \mathrm{~V}$ (Fig. 3a-b). To compare the hole mobility, parent $\mathbf{1 b}$ was also tested. The mobility of $\mathbf{1 b}$ in the saturation mode ranged from 0.072 to $0.076 \mathrm{~cm}^{2} \mathrm{~V}^{-1} \mathrm{~s}^{-1}$ with a threshold voltage ranging from -19 to $-22 \mathrm{~V}$. The averaged performance of six independent devices was $0.074 \mathrm{~cm}^{2} \mathrm{~V}^{-1} \mathrm{~s}^{-1}$ and a threshold of $-20.7 \mathrm{~V}$. The best film mobility of $1 \mathbf{b}$ was observed at $0.076 \mathrm{~cm}^{2} \mathrm{~V}^{-1} \mathrm{~s}^{-1}$ with an on/off ratio of $2.4 \times 10^{2}$ and a threshold of $-21 \mathrm{~V}$ (Fig. 3c-d). Previously, the hole mobility of hexacene $\mathbf{1 b}$ has been reported in the single-crystal phase and in the spin-coated thin-film phase by the precursor method. The best hole-transfer mobility by spincoated $1 \mathbf{b}$ was $0.035 \mathrm{~cm}^{2} \mathrm{~V}^{-1} \mathrm{~s}^{-1}$, with a similar surface treatment on $\mathrm{SiO}_{2} / \mathrm{Si}$ substrate. Although our fabrication conditions were not fully optimised, the mobility of the vacuum-deposited film was greater than that of the spin-coated one. It indicates that better crystalline films of $\mathbf{1 b}$ were formed by thermal deposition. The mobility of film 1a exhibited a larger range of randomness compared to $\mathbf{1 b}$. However, a higher hole-transfer efficiency of 1a ranging 7- to 10-folds compared with that of 1b was observed in all tested devices. This result indicated that the packing moiety and/or film morphology possessing a better charge-transfer pathway may account for the mobility. Previously, a single-crystal bromopentacene was found to exhibit a 4fold faster hole-transfer speed than that of non-substituted pentacene, while their reorganization energies were estimated to be $102 \mathrm{meV}$ and $95 \mathrm{meV}$ (B3LYP/6-31Gd level), respectively. ${ }^{23}$

DFT computations revealed that the reorganisation energy between the radical cation and ground state of 1 a was $85 \mathrm{meV}$ (B3LYP/6-31Gd level). This value was quite close to that of $\mathbf{1 b}$ (79 $\mathrm{meV}$ ), suggesting a similar energy loss during structure reorganization in the hexacenes $\mathbf{1 a}$ and $\mathbf{1 b}$.

\subsection{TEM, XRD, and AFM measurements of hexacene films}

To investigate the morphology of thin-film, we performed a surface analysis on the films 1a and 1b. Fig. 4 showed crosssection of transmission electron microscope (TEM) image of ca. $60 \mathrm{~nm}$ deposited films $1 \mathrm{a}$ and $\mathbf{1 b}$ on $\mathrm{HMDS} / \mathrm{SiO}_{2} / \mathrm{Si}$ surface. The ion milling method allows us to examine a cross-section of substrate at the interface of $\mathbf{1 a}-\mathbf{b}$ and $\mathrm{HMDS} / \mathrm{SiO}_{2} / \mathrm{Si}$. The TEM image show a good continuous growth of $\mathbf{1 a}$ and $\mathbf{1 b}$ films on $\mathrm{HMDS} / \mathrm{SiO}_{2} / \mathrm{Si}$ surface, suggesting both films were deposited uniformly on the substrate.

The parent structure of hexacene $\mathbf{1 b}$ exhibited a herringbone arrangement, where the face-to-edge stacking arrangement between adjacent molecules avoided the progress of dimerization and led to a high thermal stability in the solid state. ${ }^{\mathbf{1 4}}$ The vacuum-deposited film of $\mathbf{1 b}$ exhibited out-of-plane X-ray diffraction (XRD) peaks along (00l) direction and in-plane $\mathrm{XRD}$ along $(h k 0)$ direction (Fig. $\mathrm{S} 4 \dagger)$.

These patterns indicated that the molecules in the deposited film are oriented vertical to the surface along their long axis. In addition, this film orientation was consistent with the reported out-of-plane pattern of heat-converted film $\mathbf{1 b}$ from corresponding precursor compound. ${ }^{21}$ The (001) peak was observed at $4.84^{\circ}$ corresponding to an interplanar distance of $18.3 \AA$. This value can be compared with the $d$-spacing in the single crystal of 1b, which has been estimated to be $16.4 \AA$. It indicates that the molecules in the crystalline film $\mathbf{1 b}$ are tilted on the surface of $\mathrm{HMDS} / \mathrm{SiO}_{2} / \mathrm{Si}$ substrate. The out-of-plane and in-plane XRD peaks of vacuum-deposited film 1a exhibited (00l) and $(h k 0)$ patterns, indicating that molecules in film 1a is oriented along the long axis normal to the surface (Fig. S4†). Although film 1a exhibited weaker XRD diffraction peaks compared with that of $\mathbf{1 b}$, the $2 \theta$ angle of $1 \mathrm{a}$ observed at a smaller angle of $4.43^{\circ}$ on the $\mathrm{HMDS} / \mathrm{SiO}_{2} / \mathrm{Si}$ substrate. The $d$-spacing of bromohexacene molecules is estimated to be $20.0 \AA$. The larger $d$-spacing revealed that the molecules interact through the $a-b$ axis.

To further study of finding the difference of mobility between $\mathbf{1 a}$ and $\mathbf{1 b}$, the atomic force microscope (AFM) analysis was investigated. The films $\mathbf{1 b}$ revealed a high surface roughness of $12.01 \mathrm{~nm}$ (Fig. 5). In contrast, film 1a revealed a lower roughness of $6.48 \mathrm{~nm}$. This smoother

(a)

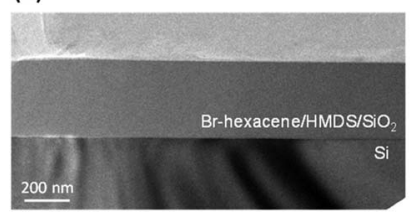

Fig. 4 TEM image of thin films $1 a(a)$ and $1 b$ (b). Top: structure of films on $\mathrm{HMDS} / \mathrm{SiO}_{2} / \mathrm{Si}$. 

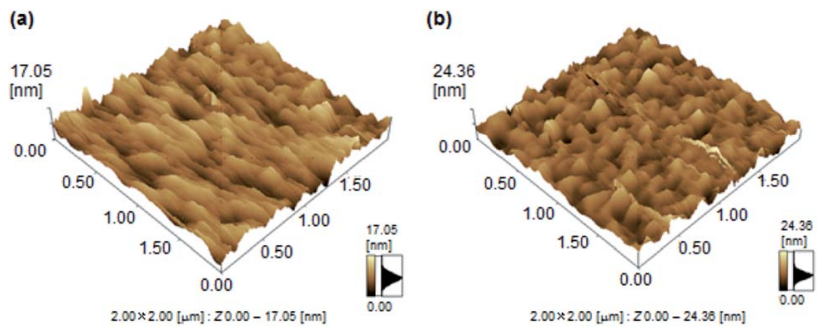

Fig. 5 AFM images of thin films of $1 a$ and $1 b$.

surface in 1a achieved a small energy loss during the transport of holes between the source and drain.

\section{Materials and methods}

\subsection{General information}

The ${ }^{1} \mathrm{H}$ and ${ }^{13} \mathrm{C}$ NMR spectra were recorded in solutions on a BrukerAV600 $(600 \mathrm{MHz})$ spectrometer. The ${ }^{1} \mathrm{H}$ and the ${ }^{13} \mathrm{C}$ NMR chemical shifts were reported as $\delta$ values (ppm) relative to external $\mathrm{Me}_{4} \mathrm{Si}$. The coupling constants $(J)$ were given in hertz. High resolution FAB mass spectra were recorded on a JMS-700 MStation spectrometer. FAB MS spectra were measured with 3-nitrobenzyl alcohol (NBA) as the matrix. Analytical thin layer chromatography (TLC) was performed on silica gel $60 \mathrm{~F}_{254}$ Merck. Column chromatography was performed on KANTOSi60N (neutral). Absorption and reflectance spectra were recorded on a SHIMADZU UV-3600. IR spectra were performed by SHIMADZU IRPrestige-21 spectrophotometer. AFM measurements were tested by SHIMADZU SPM-9700. The elemental analyses were recorded on a Yanaco $\mathrm{CHN}$ recorder MT-6. THF was distilled from sodium benzophenon ketyl. Toluene was distilled from $\mathrm{CaH}_{2}$. Other solvents and reagents were of reagent quality, purchased commercially, and used without further purification.

\section{2. ${ }^{13} \mathrm{C}$ CP/MAS NMR}

The ${ }^{13} \mathrm{C}$ CP/MAS NMR spectra were acquired with a Bruker Avance $400 \mathrm{MHz}$ NMR spectrometer, equipped with a $4 \mathrm{~mm}$ double resonance probe operating at the ${ }^{1} \mathrm{H}$ and the ${ }^{13} \mathrm{C}$ Larmor frequencies of 400.13 and $100.63 \mathrm{MHz}$, respectively. For the polarization transfer, the contact-time was set to $1.75 \mathrm{~ms}$. During data acquisition, ${ }^{1} \mathrm{H}$ decoupling by spinal-64 was applied. Powdered samples were packed in $4 \mathrm{~mm}$ zirconium oxide MAS rotors with Kel-F cap. A sample spinning frequency of $12 \mathrm{kHz}$ was used and regulated by a spinning controller within $\pm 1 \mathrm{~Hz}$. All CP-MAS experiments were carried out at ambient temperature. The ${ }^{13} \mathrm{C}$ NMR chemical shifts are referenced to the methyl signal $(=17.36 \mathrm{ppm})$ of hexamethylbenzene, which was used as an external standard. All measurements were performed in air, and the sample tube was kept in the dark between measurements.

\subsection{FET measurement}

The electrical measurements were carried out in vacuum using a semiconductor parameter analyzer (B1500A, Keysight). The saturation mobility $\left(\mu_{\text {sat }}\right)$ was extracted from the slope of the square root of the drain current plot $v s$. $V_{\mathrm{G}}$ from eqn (1).

$$
I_{\mathrm{D}, \mathrm{sat}}=\frac{W}{2 L} C_{\mathrm{i}} \mu_{\mathrm{sat}}\left(V_{\mathrm{G}}-V_{\mathrm{T}}\right)^{2}
$$

where $I_{\mathrm{D} \text {,sat }}$ is the drain-to-source saturated current; $W / L$ is the channel width to length ratio; $C_{\mathrm{i}}$ is the capacitance of the insulator per unit area, and the $V_{\mathrm{G}}$ and $V_{\mathrm{T}}$ are gate voltage and threshold voltage, respectively. A heavily doped silicon (Si) wafer was used for a back gate electrode, which was covered with a 300 nm-thick thermally grown $\mathrm{SiO}_{2}\left(C_{\mathrm{i}}=10.2 \mathrm{nF} \mathrm{cm}{ }^{-2}\right)$ as the gate insulator. Channel length $(L)$ and width $(W)$ were $2000 \mu \mathrm{m}$ and $45 \mu \mathrm{m}$.

\subsection{TEM measurement}

The organic films were vacuum sublimation of $\mathbf{1 a - b}$ under a pressure of $8 \times 10^{-6}$ torr to deposit the thin films for $350 \mathrm{~nm}$ on a $\mathrm{HMDS} / \mathrm{SiO}_{2} / \mathrm{Si}$ substrate. Cross-sectional TEM samples for all of the films were prepared by mechanical thinning and ion milling. The transmission electron microscope used in this study was a JEOL JEM-2100F, which was operated at an accelerating voltage of $200 \mathrm{kV}$.

\subsection{Synthesis of materials}

3.5.1. Synthesis of ( $6 a S, 14 a R, 15 S)$-10-bromo-17-(propan-2ylidene)-6,6a,14a,15-tetrahydro-6,15-methanohexacene-7,14-

dione 8. A solution of $1 R, 4 S-11$ (propan-2-ylidene)-1,4-dihydro1,4-methanoanthracene $3(232 \mathrm{mg}, 1.00 \mathrm{mmol})$, benzoquinone $4(108 \mathrm{mg}, 1.00 \mathrm{mmol})$, and 3,6-bis(2-pyridyl)tetrazine (248 $\mathrm{mg}$, $1.05 \mathrm{mmol})$ in toluene $(50 \mathrm{~mL})$ was heated at $95{ }^{\circ} \mathrm{C}$ for $24 \mathrm{~h}$ under a nitrogen atmosphere. After the reaction, the mixture was quenched with $30 \% \mathrm{H}_{2} \mathrm{SO}_{4}$, extracted with $\mathrm{CH}_{2} \mathrm{Cl}_{2}$, and the organic solution was dried over $\mathrm{MgSO}_{4}$ and concentrated in vacuo. The crude product was purified by a silica gel chromatograph eluted with $\mathrm{CH}_{2} \mathrm{Cl}_{2}$ to afford a mixture of endo and exo geometrical isomers of $5(163 \mathrm{mg})$ as yellow solids. The mixture was used for next step without further purification.

The mixture of 5 (163 mg, $0.519 \mathrm{mmol})$ and zinc $(600 \mathrm{mg})$ and glacial acetic acid $(50 \mathrm{~mL})$ was sonicated for $30 \mathrm{~min}$ at room temperature. After reaction, the suspension was filtered and the solution was evaporated to give the crude product. Silica gel chromatography of the crude product with $\mathrm{CH}_{2} \mathrm{Cl}_{2}$ and treatment with iced $\mathrm{MeOH}$ afforded dione $6(114 \mathrm{mg})$. The mixture was used for next step without further purification.

A mixture of diketone $6(114 \mathrm{mg}, 0.361 \mathrm{mmol})$ and 4-bromophthalaldehyde $7(76.1 \mathrm{mg}, 0.361 \mathrm{mmol})$ was dissolved in EtOH $(50 \mathrm{~mL})$. The EtOH solution was bubbled by nitrogen gas for $20 \mathrm{~min}$ to remove oxygen. To the mixture was added $10 \mathrm{wt} \%$ $\mathrm{KOH} / \mathrm{EtOH}$ solution (2-3 drops) in the nitrogen atmosphere and stirred $72 \mathrm{~h}$ at room temperature under nitrogen gas. The mixture gradually became dark, and pale-yellow powder precipitated. After reaction, the precipitate was filtered and washed with EtOH and hexane to afford endo-8 $(86.2 \mathrm{mg}, 17 \%$ in three steps). Pale yellow powder (EtOH). $\delta_{\mathrm{H}}\left(\mathrm{CDCl}_{3}, 600 \mathrm{MHz}\right)$ $1.23(\mathrm{~d}, J=4.8,6 \mathrm{H}), 3.17(\mathrm{~s}, 2 \mathrm{H}), 4.47(\mathrm{~s}, 2 \mathrm{H}), 7.45(\mathrm{dd}, J=6.0$, $3.0 \mathrm{~Hz}, 2 \mathrm{H}), 7.76(J=9.0,7.7 \mathrm{~Hz}, 1 \mathrm{H}), 7.78(\mathrm{~s}, 2 \mathrm{H}), 7.82(\mathrm{dd}, J=$ 
6.0, $2.4 \mathrm{~Hz}, 2 \mathrm{H}), 7.95(\mathrm{~d}, J=8.4 \mathrm{~Hz}, 2 \mathrm{H}), 8.24(\mathrm{~s}, 1 \mathrm{H}), 8.53(\mathrm{~s}, 1 \mathrm{H})$, $8.61(\mathrm{~s}, 1 \mathrm{H}) . \delta_{\mathrm{C}}\left(\mathrm{CDCl}_{3}, 125 \mathrm{MHz}\right) 19.7,51.3,52.9,117.9,119.0$, $124.1,125.6,127.5,127.9,128.6,131.4,131.9$, 132.2, 132.8, 132.9, 133.5, 136.0, 142.3, 143.7, 197.0, 197.8 .

3.5.2. Synthesis of $(6 S, 15 R)-10$-bromo-17-(propan-2ylidene)-6,15-dihydro-6,15-methanohexacene 9. To a solution of dione 8 (220 mg, $0.446 \mathrm{mmol}$ ) in $\mathrm{MeOH}$ (50 mL) and THF (50 $\mathrm{mL}$ ) in an ice bath was added $\mathrm{NaBH}_{4}(74 \mathrm{mg}, 1.65 \mathrm{mmol})$. After $2 \mathrm{~h}$, the reaction mixture was quenched with water. The aqueous solution containing precipitates was extracted with $\mathrm{CH}_{2} \mathrm{Cl}_{2}$. The organic layer was washed with water, and dried over anhydrous $\mathrm{MgSO}_{4}$. Removal solvent gave the diol $9(212 \mathrm{mg})$ as yellow solids. This crude compound was subjected to the next step without further purification. To a mixture of diol $\mathbf{9}$ and dried pyridine $(10 \mathrm{~mL})$ was added dropwise $\mathrm{POCl}_{3}(0.9 \mathrm{~mL})$ at $0{ }^{\circ} \mathrm{C}$. The resulting mixture was stirred at room temperature for $72 \mathrm{~h}$, then at $80{ }^{\circ} \mathrm{C}$ for another $30 \mathrm{~min}$. The mixture was poured into ice water and was extracted with $\mathrm{CH}_{2} \mathrm{Cl}_{2}$. The organic layer was washed successfully with $3 \mathrm{~N} \mathrm{HCl}$ and brine, then was dried over $\mathrm{MgSO}_{4}$. The crude product was purified by a silica gel chromatograph eluted with hexane/ $\mathrm{CH}_{2} \mathrm{Cl}_{2}(4: 1)$ to give the aromatized compound 9 (98.8 $\mathrm{mg}, 48 \%)$ as pale yellow powder. Physical data of 9: pale yellow powder (EtOH). $\delta_{\mathrm{H}}\left(\mathrm{CDCl}_{3}, 600\right.$ $\mathrm{MHz}) 1.72$ (s, 6H), 5.06 (s, 2H), 7.35 (dd, $J=6.0,3.0,2 \mathrm{H}), 7.43$ $(\mathrm{dd}, J=9.0,7.2 \mathrm{~Hz}, 1 \mathrm{H}), 7.70(J=6.0,3.0 \mathrm{~Hz}, 2 \mathrm{H}), 7.72(\mathrm{~s}, 2 \mathrm{H})$, 7.77-7.79 (m, 3H), $8.08(\mathrm{~s}, 1 \mathrm{H}), 8.12(\mathrm{~s}, 1 \mathrm{H}), 8.19(\mathrm{~s}, 1 \mathrm{H}) . \delta_{\mathrm{C}}$ $\left(\mathrm{CDCl}_{3}, 125 \mathrm{MHz}\right)$ 19.8, 51.4, 113.2, 118.3, 118.4, 118.9, 119.0, 119.02, 124.9, 125.5, 126.1, 127.7, 128.3, 129.6, 131.3, 131.7, $132.2,132.4,145.2,145.3,145.6,153.8$.

3.5.3. Synthesis of $(6 S, 15 R)-10$-bromo-6,15-dihydro-6,15methanohexacen-17-one 2a. A mixture of olefin $9(200 \mathrm{mg}$, $0.433 \mathrm{mmol}$ ) and $N$-methylmorpholine $N$-oxide (NMO) (50\% in $\left.\mathrm{H}_{2} \mathrm{O}, 1.5 \mathrm{~mL}\right)$ in a mixed solvent of acetone $(50 \mathrm{~mL})$ and $\mathrm{H}_{2} \mathrm{O}(1.5$ $\mathrm{mL}$ ) was stirred at room temperature until 9 was dissolved completely. To the solution was added a few drops of $\mathrm{OsO}_{4}(4 \%$ $\mathrm{H}_{2} \mathrm{O}$ soln). The reaction was monitored by TLC until completion, then the mixture was quenched with $15 \%$ aqueous $\mathrm{Na}_{2} \mathrm{~S}_{2} \mathrm{O}_{4}$. The aqueous solution was extracted with EtOAc, dried over $\mathrm{Na}_{2} \mathrm{SO}_{4}$, and evaporated. The product was purified by a silica gel chromatograph eluted with $\mathrm{CH}_{2} \mathrm{Cl}_{2}$ to give diol 10 (79 $\mathrm{mg}$ ), which was directly used in the next step. The diol 10 (79 $\mathrm{mg})$ and $\mathrm{PhI}(\mathrm{OAc})_{2}(120 \mathrm{mg})$ in benzene $(100 \mathrm{~mL})$ was stirred at $60{ }^{\circ} \mathrm{C}$ for $12 \mathrm{~h}$. After reaction, the mixture was cooled in an ice bath, while white precipitates formed. The solids were collected by suction filtration to give compound $2 a(59 \mathrm{mg}, 31 \%$ in two steps) as a white powder. Physical data of 2a: m.p. $181^{\circ} \mathrm{C}$. (TGA, decomp.); IR (KBr): $\nu 1786 \mathrm{~cm}^{-1}$ (s, C=O); ${ }^{13} \mathrm{C}$ CP/MAS NMR (12 $000 \mathrm{rpm}, 100 \mathrm{MHz}$ ): 54.0, 118.5, 120.6, 122.5, 123.9, 126.1, 130.5, 133.2, 135.2, 192.7 .

3.5.4. Synthesis of 2-bromohexacene 1a. Proper amount of precursor 2a was loaded in a glass container, and the powder was heated at $210{ }^{\circ} \mathrm{C}$ for 5 min under a nitrogen atmosphere. The color of $2 \mathrm{a}$ changed from white to green to give 2-bromohexacene $1 \mathrm{a}$ in a quantitative yield. M.p. $340{ }^{\circ} \mathrm{C}$. (TGA, sublime); ${ }^{13} \mathrm{C}$ CP/MAS NMR (12 $000 \mathrm{rpm}, 100 \mathrm{MHz}$ ): 123.1, 126.0; HRMS: $\mathrm{m} / \mathrm{z} 406.0387$ (M+, calcd 406.03571); EA: found, \%: C, 76.2; $\mathrm{H}$, 3.7. For $\mathrm{C}_{26} \mathrm{H}_{15} \mathrm{Br}$. Calculated, \%: C, 76.1; H, 3.7.

\section{Conclusions}

A novel hexacene precursor was successfully synthesised, which can be quantitatively converted at around $200{ }^{\circ} \mathrm{C}$ to the corresponding 2-bromohexacene. It exhibited high thermal stability over 3 months in the dark. The bromine atom affected the hexacene crystal packing and decreased the HOMO-LUMO energy gap. The thin-film of 1a was fabricated by using both spin-coating and vacuum sublimation methods, and both films exhibited exciton coupling, indicative the presence of herringbone arrangement in the polycrystalline film. The film of 1a exhibited a more efficient hole-transport property compared with that of parent $\mathbf{1 b}$. Hence, film 1a exhibits a higher hole mobility of $0.83 \mathrm{~cm}^{2} \mathrm{~V}^{-1} \mathrm{~s}^{-1}$ than that of $1 \mathbf{b}\left(0.074 \mathrm{~cm}^{2} \mathrm{~V}^{-1} \mathrm{~s}^{-1}\right)$. Although these hole mobility were lower than that of single crystal hexacene $\left(4.28 \mathrm{~cm}^{2} \mathrm{~V}^{-1} \mathrm{~s}^{-1}\right),{ }^{26}$ it was comparable with the reported value of solution-processed single crystal tricyclohexylsilylethynyloctafluorohexacene $\left(0.1 \mathrm{~cm}^{2} \mathrm{~V}^{-1} \mathrm{~s}^{-1}\right) .{ }^{31}$ To the best of our knowledge, this is the first study on the charge-transport property of a stable vacuum-deposited thin-film of hexacene for electronic device. Currently, other derivatives of halogenated hexacene are prepared, and their properties related to optoelectronic devices are being examined. The results will be reported in due course.

\section{Author's contributions}

MW designed and performed the experiments and theoretical calculations; TM, CTC, MS and SSS were synthesized, measured and analysed the materials and physical properties; TM and CA designed the devices and analysed the data; JM measured and analysed the TEM; MW and TI were measured and analysed the NMR data; MW, TM and TJC were co-wrote the manuscript; all authors gave final approval for publication.

\section{Conflicts of interest}

There are no conflicts to declare.

\section{Acknowledgements}

This work was supported by a Grant-in-Aid for Science Research (JP17H04888, JP17K19123) from the Ministry of Education, Culture, Sports, Science and Technology (MEXT), Japan, and was performed under the Cooperative Research Program of "Network Joint Research Centre for Materials and Devices (IMCE, Kyushu University)”. The computation was mainly carried out using the computer facilities at Research Institute for Information Technology, Kyushu University. MW and TM acknowledge support from I2CNER, funded by the World Premier International Research Centre Initiative (WPI), Ministry of Education, Culture, Sports, Science and Technology of Japan (MEXT), Japan. TJC and SSS are also grateful for the supports from the Ministry of Science and Technology of Taiwan and Academia Sinica. 


\section{Notes and references}

1 Q. Ye and C. Chi, Chem. Mater., 2014, 6, 4046.

2 M. Bendikov, H. M. Duong, K. Starkey, K. N. Houk, E. A. Carter and F. Wudl, J. Am. Chem. Soc., 2004, 126, 7416.

3 Y. Yang, E. R. Davidsonb and W. Yang, Proc. Natl. Acad. Sci., 2016, 113, E5098.

4 J. Mei, Y. Diao, A. L. Appleton, L. Fang and Z. Bao, J. Am. Chem. Soc., 2013, 135, 6724.

5 K. Takimiya, S. Shinamura, I. Osaka and E. Miyazaki, Adv. Mater., 2011, 23, 4347.

6 J. E. Anthony, Angew. Chem., Int. Ed., 2008, 47, 452.

7 J. Krüger, F. Garcia, F. Eisenhut, D. Skidin, J. M. Alomso, E. Guitián, D. Pérez, G. Cuniberti, F. Moresco and D. Peña, Angew. Chem., Int. Ed., 2013, 52, 3810.

8 Q. Miao, Adv. Mater., 2014, 26, 5541.

9 K. Aryanpour, A. Shukla and S. Mazumdar, J. Phys. Chem. C, 2015, 119, 6966.

10 B. Purushothaman, M. Bruzek, S. R. Parkin, A.-F. Miller and J. E. Anthony, Angew. Chem., Int. Ed., 2011, 50, 7013.

11 A. Maliakal, K. Raghavachari, H. Katz, E. Chandross and T. Siegrist, Chem. Mater., 2004, 16, 4980.

12 S. S. Zade and M. Bendikov, J. Phys. Org. Chem., 2012, 25, 452. 13 M. Watanabe, K. Y. Chen, Y. J. Chang and T. J. Chow, Acc. Chem. Res., 2013, 46, 1606.

14 M. Suzuki, T. Aotake, Y. Yamaguchi, N. Noguchi, H. Nakano, K. Nakayama and H. Yamada, J. Photochem. Photobiol., C, 2014, 18, 50 .

15 C. Tönshoff and H. F. Bettinger, Angew. Chem., Int. Ed., 2010, 49, 4125.

16 R. Einholz, T. Fang, R. Berger, P. Grüninger, A. Früh, T. Chassé, R. F. Fink and H. F. Bettinger, J. Am. Chem. Soc., 2017, 139, 4435.

17 T. Yelin, R. Korytár, N. Sukenik, R. Vardimon, B. Kumar, C. Nuckolls, F. Evers and O. Tal, Nat. Mater., 2016, 15, 444.

18 S. R. Yost, J. Lee, M. W. B. Wilson, T. Wu, D. P. McMahon, R. R. Parkhurst, N. J. Thompson, D. N. Congreve, A. Rao, K. Johnson, M. Y. Sfeir, M. G. Bawendi, T. M. Swager, R. H. Friend, M. A. Baldo and T. V. Voorhis, Nat. Chem., $2014,6,492$.

19 E. Busby, T. C. Berkelbach, B. Kumar, A. Chernikov, Y. Zhong, H. Hlaing, X.-Y. Zhu, T. F. Heinz,
M. S. Hybertsen, M. Y. Sfeir, D. R. Reichman, C. Nuckolls and O. Yaffe, J. Am. Chem. Soc., 2014, 136, 10654.

20 M. Watanabe, Y. J. Chang, S.-W. Liu, T.-H. Chao, K. Goto, M. M. Islam, C.-H. Yuan, Y.-T. Tao, T. Shinmyozu and T. J. Chow, Nat. Chem., 2012, 4, 574.

21 M. Watanabe, W.-T. Su, K.-Y. Chen, C. T. Chien, T.-H. Chao, Y. J. Chang, S.-W. Liu and T. J. Chow, Chem. Commun., 2013, 49, 2240.

22 M. Watanabe, T.-H. Chao, C.-T. Chien, S.-W. Liu, Y. J. Chang, K.-Y. Chen and T. J. Chow, Tetrahedron Lett., 2012, 53, 2284.

23 C.-T. Chien, M. Watanabe and T. J. Chow, Tetrahedron, 2015, 71, 1668.

24 H. Sirringhaus, Adv. Mater., 2014, 26, 1319.

25 Y. Diao, B. C.-K. Tee, G. Giri, J. Xu, D. H. Kim, H. A. Becerril,

R. M. Stoltenberg, T. H. Lee, G. Xue, S. C. B. Mannsfeld and Z. Bao, Nat. Mater., 2013, 12, 665.

26 M. J. Kang, I. Doi, H. Mori, E. Miyazaki, K. Takimiya, M. Ikeda and H. Kuwabara, Adv. Mater., 2011, 23, 1222.

27 K. Nakayama, Y. Hirose, J. Soeda, M. Yoshizumi, T. Uemura, M. Uno, W. Li, M. J. Kang, M. Yamagishi, Y. Okada, E. Miyazaki, Y. Nakazawa, A. Nakao, K. Takimiya and J. Takeya, Adv. Mater., 2011, 23, 1626.

28 J. Takeya, M. Yamagishi, Y. Tominari, R. Hirahara and Y. Nakazawa, Appl. Phys. Lett., 2007, 90, 102120.

29 C. Reese, W.-J. Chung, M.-M. Ling, M. Roberts and Z. Bao, Appl. Phys. Lett., 2006, 89, 202108.

30 M. L. Tang, S. C. B. Mannsfeld, Y.-S. Sun, H. A. Becerril and Z. Bao, J. Am. Chem. Soc., 2009, 131, 882.

31 B. Purushothaman, S. R. Parkin, M. J. Kendrick, D. David, J. W. Ward, L. Yu, N. Stingelin, O. D. Jurchescu, O. Ostroverkhova and J. E. Anthony, Chem. Commun., 2012, 48, 8261.

32 M. M. Payne, S. R. Parkin and J. E. Anthony, J. Am. Chem. Soc., 2005, 127, 8028.

33 B. Purushothaman, S. R. Parkin and J. E. Anthony, Org. Lett., 2010, 12, 2060.

34 B. D. Lindner, J. U. Engelhart, O. Tverskoy, A. L. Appleton, F. Rominger, A. Peters, H.-J. Himmel and U. H. F. Bunz, Angew. Chem., Int. Ed., 2011, 50, 8588.

35 Q. Miao, T.-Q. Nguyen, T. Someya, G. B. Blanchet and C. Nuckolls, J. Am. Chem. Soc., 2003, 125, 10284. 